\title{
A meta-analysis of survival after minimally invasive radical hysterectomy versus abdominal radical hysterectomy in cervical cancer: center-associated factors matter
}



Received: 12 August 2021 / Accepted: 22 November 2021 / Published online: 21 January 2022

(c) The Author(s) 2022

\begin{abstract}
Purpose To explore the possible factors that contributed to the poor performance of minimally invasive surgery (MIS) versus abdominal surgery regarding progression-free survival (PFS) and overall survival (OS) in cervical cancer.

Methods MEDLINE, EMBASE, Cochrane Library and Web of Science were searched (January 2000 to April 2021). Study selection was performed by two researchers to include studies reported oncological safety. Summary hazard ratios (HRs) and 95\% confidence intervals (CIs) were combined using random-effect model. Subgroup analyses were stratified by characteristics of disease, publication, study design and treatment center.

Results Sixty-one studies with 63,369 patients (MIS 26956 and ARH 36,049) were included. The overall-analysis revealed a higher risk of recurrence (HR 1.209; 95\% CI 1.102-1.327) and death (HR 1.124; 95\% CI 1.013-1.248) after MIS versus ARH expect in FIGO IB1 (FIGO 2009 staging) patients with tumor size less than $2 \mathrm{~cm}$. However, subgroup analyses showed comparable PFS/DFS and OS in studies published before the Laparoscopic Approach to Cervical Cancer (LACC) trial, published in European journals, conducted in a single center, performed in centers in Europe and in centers with high sample volume or high MIS sample volume.

Conclusion Our findings highlight possible factors that associated with inferior survival after MIS in cervical cancer including publication characteristics, center-geography and sample volume. Center associated factors were needed to be taken into consideration when evaluating complex surgical procedures like radical hysterectomy.
\end{abstract}

Keywords Cervical cancer - Minimally invasive surgery $\cdot$ Laparoscopic radical hysterectomy $\cdot$ Robotic-assisted radical hysterectomy · Abdominal radical hysterectomy · Oncological outcome · Overall survival · Disease-free survival ·

Recurrence

\section{Introduction}

Minimally invasive surgery (MIS), including laparoscopic radical hysterectomy (LRH) and robotic-assisted radical hysterectomy (RRH), had long been recognized as an alternative surgical approach to abdominal radical hysterectomy (ARH)

Si Sun and Jing Cai contributed equally to this work.

Qiang Yang

qiang_yang1987@163.com

Zehua Wang

zehuawang@163.net

1 Department of Obstetrics and Gynecology, Union Hospital, Tongji Medical College, Huazhong University of Science and Technology, Wuhan 430022, China with reduced operative morbidity and similar oncological safety until 2018 [1,2]. Either the preliminary data that drew an early end to a randomized controlled trial (the laparoscopic approach to cervical cancer, LACC) or the result of a large-scale observational study revealed inferiority of overall survival (OS), disease-free survival (DFS) and progressionfree survival (PFS) in patients undergoing MIS compared to ARH. These results shattered the long standing consensus of preference of MIS as primary treatment for cervical cancer and the clinical practice guideline in cervical cancer changed accordingly [3].

Before LACC, most studies compared MIS versus ARH in cervical cancer reported that MIS showed better shortterm outcomes and equivalent 5-year survival compared to ARH [4-8], hence three meta-analyses based on data before LACC reporting that there was no difference of risk 
of recurrence or death between patient underwent MIS and ARH $[9,10]$. After LACC, evidence implying inferiority of MIS for managing cervical cancer sprouted and mounted [11-14].Three recent meta-analyses evaluated the issue on basis of different inclusion criteria and ended up with different conclusions: Tanitra et al. included five studies published before 2018 and suggested no difference of PFS or OS between MIS and ARH; Nitecki et al. identified 49 studies and included 15 high-quality studies in their meta-analysis comparing MIS and ARH in patients with FIGO IA1 to IIA (FIGO 2009 staging) cervical cancer suggesting that MIS was associated with increased risks of both recurrence and death; Hwang et al. included 36 studies comparing DFS of patients undergoing LRH and ARH suggested that LRH was associated with higher risk of recurrence in patients with tumor size larger than $2 \mathrm{~cm}$ [15-17].

MIS revealed superiority of survival outcomes in prostate, colon and rectum cancers and equivalent outcomes in endometrial cancer according to the Gynecologic Oncology Group Study LAP2 trial and the laparoscopic approach to cancer of the endometrium LACE trial [18-20]. Researchers proposed several hypothetical factors that might lead to poor performance of MIS in cervical cancer such as uterine manipulator, $\mathrm{CO}_{2}$ pneumoperitoneum, learning curve, hospital volume, technique of surgeons and tumor size in patients [21,22]. Therefore, we aim to evaluate the oncological safety of MIS in cervical cancer patients stratified by characteristics of disease (FIGO stage and tumor size), publication (publication time and journal), study design (singlecenter or multi-center) and treatment center (average sample size per center) and to identify possible factors that led to the controversies of MIS among previous studies.

\section{Method}

\section{Literature search}

The literature search was conducted in Medline, Embase, Pubmed, Cochrane library and Web of Science from January 2000 to April 2021 without limitation of text availability, article type or language using the following terms: "open", "abdominal", "laparotomy", "laparoscopic", "minimally invasive", "robotic assisted", "radical hysterectomy", "surgery", "cervical cancer", "cervical carcinoma" and "carcinoma of the cervix". Additional manual search was performed by scanning the references of all included and relevant studies.

\section{Study selection and quality assessment}

Two authors screened the titles and abstracts for potentially related articles, which were further reviewed for eligibility by reference to the inclusion criteria as follows: (1) cervical cancer patients treated with minimally invasive or abdominal radical hysterectomy; (2) studies with at least two arms that compared OS, PFS or DFS; (3) patients that received surgery as primary treatment. Studies were excluded when (1) studies were published as comment, conference abstract and letter; (2) total number of patients less than 40 or at least one arm is less than 20; (3) studies did not provide sufficient data to estimate the hazard ratio (HR) and 95\% confidence interval (CI) of OS, PFS or DFS between MIS and ARH; (4) patients that received radical trachelectomy or laparoscopic assisted radical vaginal hysterectomy; (5) patients received neoadjuvant radiotherapy or chemotherapy. When population overlap existed between studies, only the most recent published study with bigger population was included. Quality assessment was conducted using the Newcastle-Ottawa Scale (NOS) for assessing the quality of nonrandomized studies in meta-analysis (Supplemental file 1).

\section{Data extraction and subgroup classification}

Two authors extracted the following data: name of first author, year of publication, journal of publication, region of journal, country and region where the studies were conducted, data source, number of centers, time span of enrollment, surgical approach, study type, cohort matching status, technique level of the surgeon, FIGO stage, histology, tumor size, lymphatic metastasis, adjuvant therapy, sample size before and after propensity score matching, HRs and 95\% CIs of OS, PFS or DFS. HRs were estimated according to Tierney et al. if not reported [23]. The extracted data were validated by a third author. Since all included studies uniformly follow the 2009 FIGO staging criteria, the FIGO classification used in this study still represented the old nomenclature.

The subgroup classification criteria were as follows: (1) FIGO stage and tumor size, studies reporting patients with FIGO stage IB1 cervical cancer were classified into tumor size $<2 \mathrm{~cm}$ or $\geq 2 \mathrm{~cm}$ subgroup; (2) year of publication, studies were classified into published before or after the LACC trial subgroup; (3) region of journal, studies were classified according to the region of journal the studies were published; (4) number of centers, studies were classified into the single-center or the multi-center group; (5) surgical approach, studies were classified into the LRH vs. ARH, the RRH vs. ARH or the MIS vs. ARH subgroup; (6) region of center, studies were classified into different 
regional subgroups according to the geographical continental location of where the surgeries were conducted; (7) sample volume, sample volume referred to annual number of radical hysterectomies conducted by all means per center reported by each study, which was estimated by number of patients that received radical hysterectomy by all means before propensity scored matching dividing number of centers then dividing number of years of recruitment. Studies were classified into high sample volume group or low sample volume group by the cur-off of median value; (8) MIS sample volume, MIS sample volume referred to annual number of radical hysterectomies conducted by MIS per center reported by each study, which was estimated by number of patients that received radical hysterectomy by MIS before propensity scored matching dividing number of centers then dividing number of years of recruitment. Studies were classified into high MIS sample volume and low MIS sample volume group by the cur-off of median value.

\section{Statistical analysis}

Random-effect model was used for all analyses despite heterogeneity [24]. Adjusted HRs and HRs after propensityscored matching were used for pooled analysis when applicable. Sample size before propensity-scored matching was used as the weight variance during meta-analysis. Heterogeneity of the included studies was assessed by $I^{2}$ and $p$ value according to Higgins et al. and was classified as small to modest $\left(I^{2}<50 \%\right)$ and high $\left(I^{2} \geq 50 \%\right)$ [25]. Publication bias was assessed by funnel plot and eager's test. A 95\% CI of HR not overlapping with 1 and a $p$ value $<0.05$ (two sided) were considered of statistical significance. All analyses were performed using STATA14 (MP-Parallel Edition, College Station, TX 77845 USA).

\section{Results}

\section{Study characteristics}

A total of 2770 citations were identified by electronic search (2671) and additional manual search (99) after removal of duplicates. 2541 were excluded by review of title and abstract. Full texts of the remaining 229 items were retrieved, of which 30 studies were reviews and comments, 60 studies compared the feasibility of different surgical plans, 40 focused on surgical complications, 32 studies did not provide sufficient data and 6 studies with smaller cohorts contained overlapping population. Finally, 61 eligible studies with 63,369 patients (MIS 26956, ARH 36049) were identified (Fig. 1). Basic characteristics of included studies were presented in Table 1. HRs and 95\% CIs of DFS/PFS

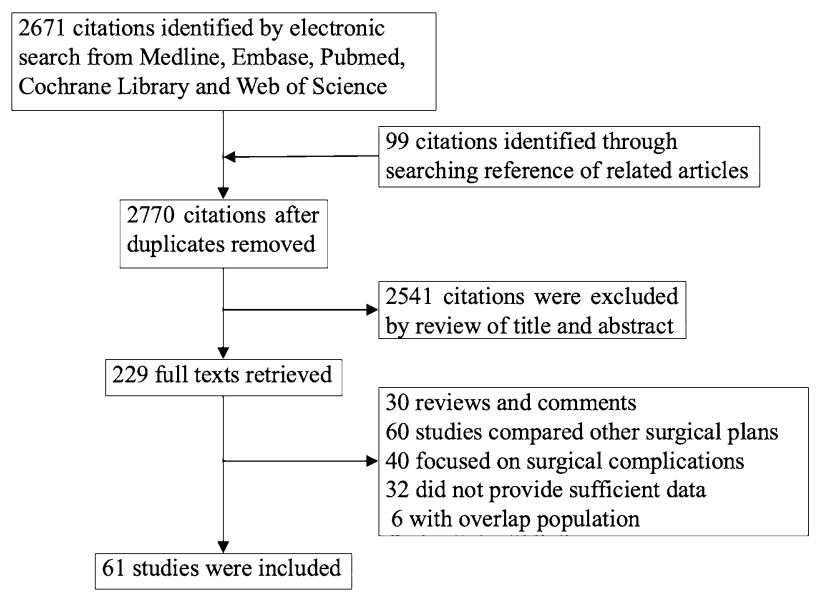

Fig. 1 Flow chart of study search and selection

and OS were extracted and pooled from 58 studies (MIS 17092, ARH 14584) and 47 studies (MIS 17979, ARH 15493), respectively [1, 2, 4-8, 11-14, 18, 22, 26-73]. Comprehensive original data were shown in Supplemental file 2.

\section{Meta-analyses of MIS versus ARH}

Fifty-eight studies were included for meta-analysis of DFS/ PFS comparing MIS to ARH. Total number of patient before propensity scored matching was 50,606 (MIS 20550 and ARH 29951) and 31,676 patients (MIS 17092 and ARH 14584) after matching were included for meta-analysis. The overall analysis revealed that patients who received MIS had higher risk of recurrence than patients that received ARH (HR 1.209; 95\% C: 1.102-1.327). However, stratified analyses showed comparable PFS/DFS between the MIS and ARH patients in studies published before the LACC trial (HR 0.906; 95\% CI 0.667-1.231), published in European Journals (HR, 0.919; 95\% CI 0.717-1.178), conducted in a single center (HR 0.929; 95\% CI 0.736-1.173), performed in centers in Europe (HR 1.027; 95\% CI 0.789-1.338) or with high MIS sample volume (HR 1.028; 95\% CI 0.857-1.234) (Table 2).

Forty-eight studies were included for meta-analysis of OS comparing MIS to ARH. Total number of patient before propensity scored matching was 59,212 (MIS 25347, ARH 33865) and 39,809 patients (MIS 21145 and ARH 18664) after matching were included for meta-analysis. Patients that received MIS had higher risk of death than patients who received ARH (HR 1.124; 95\% CI 1.013-1.248). However, there were comparable OS between patients underwent MIS and ARH in studies published before the LACC trial (HR 0.857; 95\% CI 0.628-1.169), published in European journals (HR 1.211; 95\% CI 0.922-1.589), conducted in a single center (HR 1.021; 95\% CI 0.772-1.352), performed 
Table 1 Basic characteristics of included studies

\begin{tabular}{|c|c|c|c|c|c|c|c|c|}
\hline \multirow[t]{2}{*}{ Author } & \multirow[t]{2}{*}{ Year } & \multirow[t]{2}{*}{ Region $^{1}$} & \multirow[t]{2}{*}{ Surgical approach } & \multirow[t]{2}{*}{ FIGO stage $^{3}$} & \multirow[t]{2}{*}{ Cohort matching } & \multicolumn{2}{|c|}{ No. of patients } & \multirow[t]{2}{*}{ Survival outcome } \\
\hline & & & & & & $\mathrm{MIS}^{4}$ & $\mathrm{ARH}$ & \\
\hline Gennari P & 2021 & Europe & MIS vs ARH & IA to IIB2 & Matched & 302 & 111 & OS, DFS \\
\hline Kim $S$ & 2021 & Asia & MIS vs ARH & IB1 to IIA2 & Unmatched & 110 & 38 & OS, DFS \\
\hline Levine M & 2021 & America & MIS vs ARH & IA 1 to IB 1 & Unmatched & 82 & 44 & OS, DFS \\
\hline $\mathrm{Li} \mathrm{L}$ & 2021 & Asia & MIS vs ARH & IA to IIA & Unmatched & 282 & 280 & OS, DFS \\
\hline Rodriguez J & 2021 & Mixed $^{2}$ & LRH vs ARH & IA2 IB1 & Matched & 681 & 698 & OS, DFS \\
\hline Zaccarini F & 2021 & Europe & LRH vs ARH & IA to IIIA & Matched & 223 & 41 & OS, DFS \\
\hline Bogani G & 2020 & Europe & LRH vs ARH & IB1 to IIB & Unmatched & 235 & 823 & DFS \\
\hline Brandt B & 2020 & America & MIS vs ARH & IA 1 to IB 1 & Matched & 117 & 79 & OS, DFS \\
\hline Chen B & 2020 & Asia & RRH vs ARH & IA 1 to IIA2 & Matched & 1048 & 9266 & OS, DFS \\
\hline Chen $\mathrm{C}$ & 2020 & Asia & LRH vs ARH & $\mathrm{IB} 1 \leq 2 \mathrm{~cm}$ & Unmatched & 963 & 1634 & OS, DFS \\
\hline Chen X & 2020 & Asia & LRH vs ARH & $\mathrm{IB} 1 \leq 2 \mathrm{~cm}$ & Unmatched & 129 & 196 & DFS \\
\hline Chiva L & 2020 & Europe & MIS vs ARH & IB1 & Matched & 291 & 402 & OS, DFS \\
\hline Dai D & 2020 & Asia & LRH vs ARH & IB & Matched & 213 & 213 & OS, DFS \\
\hline Eoh K & 2020 & Asia & RRH vs ARH & IA to IB & Matched & 168 & 142 & DFS \\
\hline Guo C & 2020 & Asia & MIS vs ARH & IA 1 to IIA1 & Matched & 2439 & 813 & OS, DFS \\
\hline He J & 2020 & Asia & LRH vs ARH & IA1 to IB1 & Matched & 2915 & 5545 & OS, DFS \\
\hline $\mathrm{Hu} \mathrm{T}$ & 2020 & Asia & LRH vs ARH & IA2, IB 1, IIA1 & Matched & 406 & 406 & OS, DFS \\
\hline Pedone L & 2020 & Europe & LRH vs ARH & IA 1 to IIA1 & Matched & 137 & 114 & DFS \\
\hline Qin M & 2020 & Asia & LRH vs ARH & IA 1 to IB 1 & Unmatched & 172 & 84 & OS, DFS \\
\hline Uppal S & 2020 & America & MIS vs ARH & IA 1 to IB 1 & Matched & 560 & 255 & OS, DFS \\
\hline Wenzel H & 2020 & Europe & MIS vs ARH & IA2, IB 1, IIA1 & Matched & 369 & 740 & OS, DFS \\
\hline Yang J & 2020 & America & RRH vs ARH & IA2 to IIA & Matched & 152 & 181 & OS, DFS \\
\hline Yang W & 2020 & Asia & LRH vs ARH & IA IB1 IIA1 & Matched & 142 & 186 & OS, DFS \\
\hline Yuce T & 2020 & America & MIS vs ARH & IA to IB & Matched & 1993 & 1707 & OS \\
\hline Alfonzo E & 2019 & Europe & RRH vs ARH & IA1 to IB 1 & Unmatched & 628 & 236 & OS, DFS \\
\hline Cusimano M & 2019 & America & MIS vs ARH & IA, IB, II+ & Unmatched & 256 & 278 & OS, DFS \\
\hline Doo D & 2019 & America & RRH vs ARH & IB1 & Unmatched & 49 & 56 & OS, DFS \\
\hline Gil-Moreno A & 2019 & Europe & MIS vs ARH & IA2, IB1, IIA1 & Unmatched & 112 & 76 & OS, DFS \\
\hline $\mathrm{Hu} \mathrm{T}$ & 2019 & Asia & LRH vs ARH & IA to IIA & Unmatched & 255 & 423 & DFS \\
\hline Kanao H & 2019 & Asia & LRH vs ARH & IB1 to IIB & Matched & 80 & 83 & OS \\
\hline Kim J & 2019 & Asia & LRH vs ARH & - & Matched & 3100 & 3235 & OS, DFS \\
\hline Kim S & 2019 & Asia & LRH vs ARH & IB1 to IB2 & Unmatched & 158 & 435 & OS, DFS \\
\hline Liu Y & 2019 & Asia & LRH vs ARH & IB & Unmatched & 271 & 135 & OS, DFS \\
\hline Matanes E & 2019 & Europe & RRH vs ARH & IA1 to IIB & Matched & 74 & 24 & OS, DFS \\
\hline Paik E & 2019 & Asia & LRH vs ARH & IB1 to IIA1 & Matched & 119 & 357 & OS, DFS \\
\hline Ratiu D & 2019 & Europe & LRH vs ARH & IA1 to IIB & Matched & 34 & 41 & OS, DFS \\
\hline Wang W & 2019 & Asia & LRH vs ARH & IB2 to IIB & Unmatched & 231 & 197 & OS, DFS \\
\hline Yuan Z & 2019 & Asia & LRH vs ARH & IA2 to IIA2 & Unmatched & 98 & 98 & OS \\
\hline Alexander M & 2018 & America & MIS vs ARH & IA to IB & Matched & 1225 & 1236 & OS, DFS \\
\hline Corrado G & 2018 & Europe & $\begin{array}{l}\text { LRH vs ARH } \\
\text { RRH vs ARH }\end{array}$ & IB1 & Unmatched & 152 & 101 & DFS \\
\hline Guo J & 2018 & Asia & LRH vs ARH & IA1 to IIA2 & Unmatched & 412 & 139 & OS, DFS \\
\hline Pedro R & 2018 & Mixed $^{2}$ & MIS vs ARH & IA 1 to IB 1 & Unmatched & 319 & 312 & DFS \\
\hline Driver & 2017 & America & MIS vs ARH & IA to IIB & Unmatched & 101 & 282 & OS, DFS \\
\hline $\mathrm{He} \mathrm{H}$ & 2017 & Asia & LRH vs ARH & IA 2 to IIA2 & Unmatched & 1071 & 792 & OS, DFS \\
\hline Shah C & 2017 & America & RRH vs ARH & IA 1 to IB2 & Matched & 107 & 202 & DFS \\
\hline Wallin E & 2017 & Europe & RRH vs ARH & IA1 to IIA2 & Unmatched & 149 & 155 & OS, DFS \\
\hline Mendivil A & 2016 & America & $\begin{array}{l}\text { LRH vs ARH } \\
\text { RRH vs ARH }\end{array}$ & IA2 to IIB & Unmatched & 49 & 39 & OS, DFS \\
\hline
\end{tabular}


Table 1 (continued)

\begin{tabular}{llllllccc}
\hline Author & Year & Region & Surgical approach & FIGO stage & Cohort matching & No. of patients & Survival outcome \\
\cline { 6 - 8 } & & & & & MIS & ARH \\
\hline Sert B & 2016 & America & RRH vs ARH & IA1 to IB2 + & Unmatched & 259 & 232 & OS, DFS \\
Wang W & 2016 & Asia & LRH vs ARH & IA2 to IIA2 & Unmatched & 203 & 203 & OS, DFS \\
Zanagnolo V & 2016 & Europe & RRH vs ARH & IA2 to IIA2 & Unmatched & 203 & 104 & DFS \\
Ditto A & 2015 & Europe & LRH vs ARH & IA2 IB1 & Matched & 60 & 60 & OS, DFS \\
Xiao M & 2015 & Asia & LRH vs ARH & IA2 to IIB & Matched & 106 & 48 & OS, DFS \\
Yang L & 2015 & Asia & LRH vs ARH & IA2 to IIB & Unmatched & 1052 & 477 & OS, DFS \\
Bogani G & 2014 & Europe & LRH vs ARH & IA2 to IIB & Unmatched & 65 & 65 & OS, DFS \\
Toptas T & 2014 & Europe & LRH vs ARH & IA2 to IB1 & Unmatched & 22 & 46 & OS, DFS \\
Ghezzi F & 2013 & Europe & LRH vs ARH & IB1 to IIB & Unmatched & 68 & 273 & DFS \\
Park J & 2013 & Asia & LRH vs ARH & IB2 and IIA2 & Matched & 115 & 188 & OS, DFS \\
Choi C & 2012 & Asia & LRH vs ARH & IA1-IIA & Matched & 105 & 99 & DFS \\
Nam J & 2012 & Asia & LRH vs ARH & IA2 to IIA2 & Unmatched & 263 & 263 & OS, DFS \\
Lee E & 2011 & Asia & LRH vs ARH & IA1 to IIB & Unmatched & 24 & 48 & OS, DFS \\
Yang Z & 2011 & Asia & LRH v ARH & IA2 to IIA2 & Matched & 85 & 85 & DFS \\
Cantrell L & 2010 & America & RRH vs ARH & IA1 to IIB & Matched & 63 & 63 & DFS \\
Malzoni M & 2009 & Europe & LRH vs ARH & IA2 IB1 & Matched & 65 & 62 & DFS \\
Sobiczewski P & 2009 & Europe & LRH vs ARH & IA, IB1, IIA & Matched & 22 & 58 & OS, DFS \\
Li G & 2007 & Asia & LRH vs ARH & IB1 to IIA1 & Matched & 90 & 35 & OS, DFS
\end{tabular}

$M I S$ minimally invasive surgery, $L R H$ laparoscopic radical hysterectomy, $R R H$ robotic-assisted radical hysterectomy, $A R H$ abdominal radical hysterectomy, $O S$ overall survival, DFS disease-free survival

${ }^{1}$ Region of centers where the studies were conducted

${ }^{2}$ Mixed referred to intercontinental

${ }^{3}$ FIGO 2009 staging, FIGO IA1 specifically referred to those IA1 with LVSI

${ }^{4}$ MIS included LRH and RRH

in centers in Europe (HR 1.016; 95\% CI 0.710-1.452) or Asia (HR, 1.028; 95\% CI 0.906-1.166) and with a high MIS sample volume (HR 1.016; 95\% CI 0.843-1.225). (Table 3).

\section{Meta-analyses of LRH versus ARH and RRH versus ARH}

Thirty-four studies were included for meta-analysis of DFS/PFS comparing LRH to ARH. Total number of patient before propensity scored matching was 26,886 (MIS 11270 and ARH 15252) and 17,778 patients (MIS 9284 and ARH 8494) after matching were included for meta-analysis. Overall, patients that received LRH had higher risk of recurrence than patients who received ARH (HR 1.277; 95\% CI 1.143-1.426). However, stratified analyses showed comparable PFS/DFS between patients that underwent MIS and ARH in studies published before the LACC trial (HR 0.858; 95\% CI 0.668-1.103), published in European (HR 0.858; 95\% CI
0.640-1.151) and Asian (HR 1.105; 95\% CI 0.856-1.426) journals, with a single-center study design (HR 0.996; 95\% CI 0.768-1.291), conducted in centers in Europe (HR 1.226; 95\% CI 0.914-1.643) or in centers with high MIS sample volume (HR 0.971; 95\% CI 0.790-1.194) (Table 4).

Twenty-five studies were included for meta-analysis of OS comparing LRH to ARH. The total number of patients before propensity scored matching was 30,063 (MIS 13245 and ARH 10633), and 21,945 (MIS 11312 and ARH 10633) after matching were included for meta-analysis. Overall, there was no difference of OS between patients that underwent LRH and ARH. However, LRH was associated with a poor OS in studies published in American journals (HR 1.258 ; 95\% CI 1.023-1.547) and conducted in centers with a low MIS sample volume (HR 1.249; 95\% CI 1.007-1.550), but with a better OS in studies published in Asian journals (HR 0.718; 95\% CI 0.587-0.877) (Table 5).

Thirteen studies were included for meta-analysis of PFS/ DFS comparing RRH to ARH. The total number of patient before propensity scored matching was 14,044 (RRH 3103 
Table 2 Sub-group analyses of all studies comparing diseasefree survival/progression-free survival between patients undergoing MIS and ARH

\begin{tabular}{|c|c|c|c|c|c|c|}
\hline & \multirow[t]{2}{*}{ No. of studies } & \multicolumn{3}{|c|}{ No. of patients } & \multirow[t]{2}{*}{ HR $(95 \% \mathrm{CI})$} & \multirow[t]{2}{*}{$p$ value $I^{2}$ value } \\
\hline & & MIS & $\mathrm{ARH}$ & Total & & \\
\hline Overall analysis & 58 & 17,092 & 14,584 & 31,676 & $1.209(1.102-1.327)$ & $<0.00154 .0 \%$ \\
\hline \multicolumn{7}{|l|}{ Publication time-point } \\
\hline Before LACC & 23 & 4753 & 3951 & 8704 & $0.906(0.667-1.231)$ & $0.52944 .5 \%$ \\
\hline After LACC & 35 & 12,339 & 10,633 & 22,972 & $1.294(1.184-1.415)$ & $<0.00159 .8 \%$ \\
\hline \multicolumn{7}{|l|}{ Region of journal $^{1}$} \\
\hline Europe & 16 & 2924 & 2552 & 5476 & $0.919(0.717-1.178)$ & $0.505 \mathbf{6 5 . 1 \%}$ \\
\hline America & 32 & 10,161 & 8723 & 18,884 & $1.254(1.129-1.393)$ & $<0.00155 .8 \%$ \\
\hline Asia & 9 & 3897 & 3271 & 7168 & $1.421(1.057-1.909)$ & $\mathbf{0 . 0 2 0} 43.2 \%$ \\
\hline \multicolumn{7}{|l|}{ No. of center } \\
\hline Single center & 33 & 12,926 & 11,097 & 24,023 & $0.929(0.736-1.173)$ & $0.53532 .7 \%$ \\
\hline Multi-center & 25 & 4166 & 3487 & 7653 & $1.329(1.209-1.461)$ & $<0.00168 .7 \%$ \\
\hline \multicolumn{7}{|l|}{ Surgical approach ${ }^{2}$} \\
\hline LRH vs ARH & 34 & 9083 & 8215 & 17,298 & $1.193(1.042-1.366)$ & $\mathbf{0 . 0 1 1} 48.1 \%$ \\
\hline RRH vs ARH & 13 & 2333 & 2271 & 4604 & $1.247(1.065-1.460)$ & $0.00660 .2 \%$ \\
\hline LRH\&RRH vs ARH & 13 & 9774 & 5676 & 4098 & $1.193(0.966-1.474)$ & $0.10164 .3 \%$ \\
\hline \multicolumn{7}{|l|}{ Region of center ${ }^{3}$} \\
\hline Europe & 18 & 5189 & 2454 & 2735 & $1.027(0.789-1.338)$ & $0.84361 .0 \%$ \\
\hline America & 11 & 3749 & 1928 & 1821 & $1.428(1.045-1.950)$ & $\mathbf{0 . 0 2 5} 48.1 \%$ \\
\hline Asia & 27 & 20,728 & 11,710 & 9018 & $1.213(1.092-1.347)$ & $<\mathbf{0 . 0 0 1} 43.0 \%$ \\
\hline \multicolumn{7}{|l|}{ Sample volume ${ }^{4}$} \\
\hline High volume & 29 & 17,521 & 10,288 & 7233 & $1.144(1.012-1.294)$ & $0.03262 .0 \%$ \\
\hline Low volume & 27 & 12,353 & 6144 & 6209 & $1.289(1.112-1.493)$ & $\mathbf{0 . 0 0 1} 41.7 \%$ \\
\hline Mixed volume & 2 & 1802 & 660 & 1142 & $1.679(1.196-2.358)$ & $0.00369 .1 \%$ \\
\hline \multicolumn{7}{|l|}{ MIS sample volume ${ }^{4}$} \\
\hline High volume & 28 & 15,024 & 9229 & 5795 & $1.028(0.857-1.234)$ & $0.765 \mathbf{5 6 . 4 \%}$ \\
\hline Low volume & 28 & 14,850 & 7203 & 7647 & $1.319(1.188-1.464)$ & $<\mathbf{0 . 0 0 1} 49.7 \%$ \\
\hline Mixed volume & 2 & 1802 & 660 & 1142 & $1.679(1.196-2.358)$ & $0.00369 .1 \%$ \\
\hline
\end{tabular}

Data in bold style were of statistical significance to faciliate reading

$M I S$ minimally invasive surgery, $L R H$ laparoscopic radical hysterectomy, $R R H$ robotic-assisted radical hysterectomy, $A R H$ abdominal radical hysterectomy, $H R$ hazard ratio, $C I$ confidence interval

${ }^{1}$ One study published in an Australian journal was not presented in the table

${ }^{2}$ Two studies reported both LRH and RRH

${ }^{3}$ Two studies conducted intercontinental were not presented in the table

${ }^{4}$ Sample volume and MIS sample volume were estimated by total number of patients received radical hysterectomy by all means and by MIS before propensity scored matching dividing number of centers and years of recruitment and ARH 10941), and 5084 (MIS 2534 and ARH 2550) after matching were included for meta-analysis. Patients that received RRH had higher risk of death than patients who received ARH (HR 1.303; 95\% CI 1.130-1.503). However, there were comparable OS between patients that underwent MIS and ARH in studies conducted in a single center (HR 1.516 ; 95\% CI 0.970-2.369) or in Europe (HR 1.376; 95\% CI 0.940-2.014) (Table 6).

Eleven studies with 4470 patients (RRH 2217, ARH 2253) were included to evaluate OS of patients that received RRH. There was no difference of OS between RRH and ARH.

\section{Meta-analyses of MIS versus ARH in patients with FIGO IB1 cervical cancer}

Seventeen studies with 13,944 patients after matching (MIS 7168, 6776) specifically compared patients with FIGO IB1 cervical cancer underwent MIS and ARH. Overall, MIS was associated with increased risk of recurrence and progression in patients with FIGO IB1 cervical cancer (HR 1.515; 95\% CI 1.271-1.805). Subgroup analyses showed comparable OS between patients that underwent MIS and ARH in studies with a single-center design (HR 1.558; 95\% CI 0.911-2.664), conducted in Europe (HR 1.241; 95\% CI 
Table 3 Sub-group analyses of all studies comparing overall survival between patients undergoing MIS and ARH

\begin{tabular}{|c|c|c|c|c|c|c|c|}
\hline & \multirow[t]{2}{*}{ No. of studies } & \multicolumn{3}{|c|}{ No. of patients } & \multirow[t]{2}{*}{ HR $(95 \% \mathrm{CI})$} & \multirow[t]{2}{*}{$p$ value } & \multirow[t]{2}{*}{$I^{2}$ value } \\
\hline & & MIS & $\mathrm{ARH}$ & Total & & & \\
\hline Overall analysis & 48 & 21,145 & 18,664 & 39,809 & $1.124(1.013-1.248)$ & 0.028 & $66.4 \%$ \\
\hline \multicolumn{8}{|c|}{ Publication time-point } \\
\hline Before LACC & 15 & 3815 & 3048 & 6863 & $0.857(0.628-1.169)$ & 0.329 & $0.0 \%$ \\
\hline After LACC & 33 & 17,330 & 15,616 & 32,946 & 1.175 (1.051-1.312) & 0.004 & $76.3 \%$ \\
\hline \multicolumn{8}{|c|}{ Region of journal $^{1}$} \\
\hline Europe & 11 & 2111 & 2008 & 4119 & $1.211(0.922-1.589)$ & 0.169 & $35.8 \%$ \\
\hline America & 26 & 15,362 & 24,250 & 39,612 & 1.293 (1.126-1.485) & $<0.001$ & $33.2 \%$ \\
\hline Asia & 10 & 7022 & 7067 & 14,089 & $0.751(0.616-0.914)$ & 0.004 & $\mathbf{7 8 . 2 \%}$ \\
\hline \multicolumn{8}{|l|}{ No. of center } \\
\hline Single center & 23 & 3081 & 2641 & 5722 & $1.021(0.772-1.352)$ & 0.882 & $0.0 \%$ \\
\hline Multi-center & 25 & 14,898 & 12,852 & 27,750 & $1.138(1.017-1.274)$ & 0.024 & $79.5 \%$ \\
\hline \multicolumn{8}{|c|}{ Surgical approach ${ }^{2}$} \\
\hline LRH vs ARH & 26 & 11,312 & 10,633 & 21,945 & $1.087(0.956-1.235)$ & 0.204 & $75.5 \%$ \\
\hline RRH vs ARH & 11 & 2217 & 2253 & 4470 & $1.094(0.856-1.399)$ & 0.474 & $\mathbf{5 3 . 9 \%}$ \\
\hline MIS vs ARH & 14 & 7817 & 6057 & 13,874 & $1.245(0.998-1.552)$ & 0.052 & $46.6 \%$ \\
\hline \multicolumn{8}{|l|}{ Region of center ${ }^{3}$} \\
\hline Europe & 13 & 1917 & 2113 & 4030 & $1.016(0.710-1.452)$ & 0.932 & $28.7 \%$ \\
\hline America & 12 & 4270 & 4059 & 8329 & $1.399(1.113-1.759)$ & 0.004 & $39.2 \%$ \\
\hline Asia & 21 & 13,958 & 11,482 & 25,440 & $1.028(0.906-1.166)$ & 0.672 & $72.4 \%$ \\
\hline \multicolumn{8}{|l|}{ Sample volume ${ }^{4}$} \\
\hline High volume & 21 & 9111 & 6270 & 15,381 & $1.141(0.963-1.351)$ & 0.128 & $44.9 \%$ \\
\hline Low volume & 22 & 5765 & 5561 & 11,326 & $1.227(1.002-1.502)$ & 0.047 & $23.7 \%$ \\
\hline Mixed volume & 5 & 6269 & 6833 & 13,102 & $0.980(0.849-1.132)$ & 0.786 & $94.5 \%$ \\
\hline \multicolumn{8}{|c|}{ MIS sample volume ${ }^{4}$} \\
\hline High volume & 22 & 8109 & 4960 & 13,069 & $1.016(0.843-1.225)$ & 0.867 & $6.3 \%$ \\
\hline Low volume & 21 & 6767 & 6871 & 13,638 & $1.267(1.067-1.505)$ & 0.007 & $42.7 \%$ \\
\hline Mixed volume & 5 & 6269 & 6833 & 13,102 & $0.980(0.849-1.132)$ & 0.786 & $94.5 \%$ \\
\hline
\end{tabular}

Data in bold style were of statistical significance to faciliate reading

$M I S$ minimally invasive surgery, $L R H$ laparoscopic radical hysterectomy, $R R H$ robotic-assisted radical hysterectomy, $A R H$ abdominal radical hysterectomy, $H R$ hazard ratio, $C I$ confidence interval

${ }^{1}$ One study published in an Australian journal was not presented in the table;

${ }^{2}$ Two studies reported both LRH and RRH;

${ }^{3}$ Two studies conducted intercontinental were not presented in the table;

${ }^{4}$ Sample volume and MIS sample volume were estimated by total number of patients received radical hysterectomy by all means and by MIS before propensity scored matching dividing number of centers and years of recruitment
0.891-1.728) and with high sample volume (HR 1.254; 95\% CI 0.862-1.824) or high MIS sample volume (HR 1.264; 95\% CI 0.876-1.824) (Table 7). Moreover, MIS was correlated with increased risk of recurrence in patients with tumor size $\geq 2 \mathrm{~cm}$ (HR 1.787; 95\% CI 1.396-2.286) but not $<2 \mathrm{~cm}$ (HR 1.257; 95\% CI 0.884-1.789). While in 8375 FIGO IB 1 patients with tumor $<2 \mathrm{~cm}$ (MIS 4333, ARH 4042), although overall meta-analysis showed comparable PFS/DFS between patients that underwent MIS and ARH, MIS was correlated with increased risk of recurrence in studies conducted in Asia (HR 1.398; 95\% CI 1.061-1.843) and in studies with low sample volume (HR 1.552; 95\% CI 1.190-2.024) or low MIS sample volume (HR 1.527; $95 \%$ CI 1.183-1.969) (Table 8).

\section{Publication bias}

Publication bias was first evaluated by visual inspection of funnel plots and then Egger's test. Visual inspection of funnel plots for studies comparing DFS/PFS and OS of 
Table 4 Sub-group analysis of studies comparing diseasefree/progression-free survival between patients undergoing LRH and ARH

\begin{tabular}{|c|c|c|c|c|c|c|c|}
\hline & \multirow[t]{2}{*}{ No. of studies } & \multicolumn{3}{|c|}{ No. of patients } & \multirow[t]{2}{*}{ HR $(95 \% \mathrm{CI})$} & \multirow[t]{2}{*}{$p$ value } & \multirow[t]{2}{*}{$I^{2}$ value } \\
\hline & & MIS & ARH & Total & & & \\
\hline Overall analysis & 34 & 9284 & 8494 & 17,778 & $1.277(1.143-1.426)$ & $<0.001$ & $45.2 \%$ \\
\hline \multicolumn{8}{|c|}{ Publication time-point } \\
\hline Before LACC & 17 & 3871 & 2912 & 6783 & $0.858(0.668-1.103)$ & 0.233 & $0.0 \%$ \\
\hline After LACC & 17 & 5413 & 5582 & 10,995 & $1.474(1.307-1.662)$ & $<0.001$ & $\mathbf{5 5 . 7} \%$ \\
\hline \multicolumn{8}{|l|}{ Region of journal } \\
\hline Europe & 10 & 1731 & 1378 & 3266 & $0.858(0.640-1.151)$ & 0.306 & $9.9 \%$ \\
\hline America & 17 & 4331 & 4765 & 9096 & $1.453(1.278-1.652)$ & $<0.001$ & $46.1 \%$ \\
\hline Asia & 7 & 3508 & 2789 & 6297 & $1.105(0.856-1.426)$ & 0.444 & $36.0 \%$ \\
\hline \multicolumn{8}{|l|}{ No. of center } \\
\hline Single center & 21 & 2607 & 2244 & 4851 & $0.996(0.768-1.291)$ & 0.973 & $0.0 \%$ \\
\hline Multi-center & 13 & 6677 & 6250 & 12,927 & $1.358(1.202-1.535)$ & $<0.001$ & $67.2 \%$ \\
\hline \multicolumn{8}{|l|}{ Region of center ${ }^{1}$} \\
\hline Europe & 10 & 722 & 891 & 1613 & $1.226(0.914-1.643)$ & 0.174 & $46.6 \%$ \\
\hline America & 1 & - & - & - & - & - & - \\
\hline Asia & 22 & 7832 & 6866 & 14,698 & $1.262(1.115-1.428)$ & $<0.001$ & $50.2 \%$ \\
\hline \multicolumn{8}{|l|}{ Sample volume ${ }^{2}$} \\
\hline High volume & 17 & 4760 & 3693 & 8453 & $1.096(0.923-1.302)$ & 0.296 & $49.0 \%$ \\
\hline Low volume & 17 & 4524 & 4801 & 9325 & $1.396(1.209-1.612)$ & $<0.001$ & $43.1 \%$ \\
\hline \multicolumn{8}{|c|}{ MIS sample volume ${ }^{2}$} \\
\hline High volume & 17 & 4894 & 3585 & 8479 & $0.971(0.790-1.194)$ & 0.781 & $35.7 \%$ \\
\hline Low volume & 17 & 4390 & 4909 & 9299 & 1.457 (1.279-1.660) & $<0.001$ & $37.6 \%$ \\
\hline
\end{tabular}

Data in bold style were of statistical significance to faciliate reading

$M I S$ minimally invasive surgery, $L R H$ laparoscopic radical hysterectomy, $R R H$ robotic-assisted radical hysterectomy, $A R H$ abdominal radical hysterectomy, $H R$ hazard ratio, $C I$ confidence interval

${ }^{1}$ One study was intercontinental

${ }^{2}$ Sample volume and MIS sample volume were estimated by total number of patients received radical hysterectomy by all means and by MIS before propensity scored matching dividing number of centers and years of recruitment patients undergoing MIS and ARH showed a slight asymmetry (Figs. 2 and 3). The results of Egger's tests suggested that there was no publication bias for pooled DFS/PFS $(p=0.074)$ and OS $(p=0.052)$. Sensitivity analysis was performed by sequentially trimming and adding each included study. The results remained unchanged.

\section{Discussion}

Overall, compared to ARH, MIS was associated with increased risk of disease progression or recurrence and increased risk of death in women with early stage cervical cancer. Comparable oncological outcomes between patients that received MIS and ARH was found in the meta-analysis in FIGO IB1 patients with tumor size less than $2 \mathrm{~cm}$ and in studies published before the LACC trial, published in European journals, conducted in a single center, performed in centers in Europe or with a high MIS sample volume, while the inferiority of MIS was found in the meta-analysis of studies published after the LACC trial, with a multi-center study design, conducted in Asia and America, or in centers with a low MIS sample volume. These findings delineate the complexity of the factors impacting MIS outcomes reported in published studies and may trigger rethinking about the surgical approaches for radical hysterectomy in early stage cervical cancers.

We found comparable oncological safety in patients undergoing MIS compared with ARH in studies published before the LACC trial but inferiority of MIS in studies published after the LACC trial, which was consistent with previous meta-analyses [9, 10,15-17]. Additionally, studies published in American journals showed a poor PFS in patients that received MIS while studies published in European and Asian journals showed comparable PFS between patients undergoing MIS and ARH. We assumed 
Table 5 Sub-group analysis of studies comparing overall survival between patients undergoing LRH and ARH

\begin{tabular}{|c|c|c|c|c|c|c|c|}
\hline & \multirow[t]{2}{*}{ No. of studies } & \multicolumn{3}{|c|}{ No. of patients } & \multirow[t]{2}{*}{ HR $(95 \% \mathrm{CI})$} & \multirow[t]{2}{*}{$p$ value } & \multirow[t]{2}{*}{$I^{2}$ value } \\
\hline & & LRH & $\mathrm{ARH}$ & Total & & & \\
\hline Overall analysis & 25 & 11,312 & 10,633 & 21,945 & $0.945(0.818-1.091)$ & 0.440 & $66.2 \%$ \\
\hline \multicolumn{8}{|c|}{ Publication time-point } \\
\hline Before LACC & 11 & 3183 & 2446 & 5629 & $0.861(0.619-1.199)$ & 0.712 & $0.0 \%$ \\
\hline After LACC & 14 & 8129 & 8187 & 16,316 & $0.971(0.828-1.138)$ & 0.377 & $80.5 \%$ \\
\hline \multicolumn{8}{|l|}{ Region of journal } \\
\hline Europe & 7 & 949 & 693 & 1642 & $0.867(0.478-1.572)$ & 0.638 & $0.0 \%$ \\
\hline America & 11 & 3769 & 4063 & 7832 & $1.258(1.023-1.547)$ & 0.030 & $12.6 \%$ \\
\hline Asia & 7 & 6594 & 5877 & 12,471 & $0.718(0.587-0.877)$ & 0.001 & $66.3 \%$ \\
\hline \multicolumn{8}{|l|}{ No. of center } \\
\hline Single center & 15 & 1839 & 1695 & 3534 & $0.954(0.642-1.420)$ & 0.529 & $0.0 \%$ \\
\hline Multi-center & 10 & 6307 & 5767 & 12,074 & $0.942(0.811-1.096)$ & 0.441 & $84.5 \%$ \\
\hline \multicolumn{8}{|l|}{ Region of center ${ }^{1}$} \\
\hline Europe & 6 & 758 & 334 & 424 & $0.934(0.453-1.926)$ & 0.853 & $0.0 \%$ \\
\hline America & 1 & - & - & - & - & - & - \\
\hline Asia & 17 & 10,248 & 9472 & 19,720 & $0.908(0.782-1.053)$ & 0.848 & $\mathbf{7 1 . 8} \%$ \\
\hline \multicolumn{8}{|l|}{ Sample volume ${ }^{2}$} \\
\hline High volume & 11 & 3900 & 3027 & 6927 & $0.916(0.685-1.225)$ & 0.553 & $32.4 \%$ \\
\hline Low volume & 13 & 4246 & 4435 & 8681 & $1.233(0.990-1.536)$ & 0.062 & $0.0 \%$ \\
\hline Mixed volume & 1 & - & - & - & - & - & - \\
\hline \multicolumn{8}{|c|}{ MIS sample volume ${ }^{2}$} \\
\hline High volume & 13 & 4091 & 3047 & 7138 & $0.902(0.669-1.216)$ & 0.497 & $20.1 \%$ \\
\hline Low volume & 11 & 4055 & 4415 & 8470 & $1.249(1.007-1.550)$ & 0.043 & $15.2 \%$ \\
\hline Mixed volume & 1 & - & - & - & - & - & - \\
\hline
\end{tabular}

Data in bold style were of statistical significance to faciliate reading

$M I S$ minimally invasive surgery, $L R H$ laparoscopic radical hysterectomy, $R R H$ robotic-assisted radical hysterectomy, $A R H$ abdominal radical hysterectomy, $H R$ hazard ratio, $C I$ confidence interval

${ }^{1}$ One study was intercontinental

${ }^{2}$ Sample volume and MIS sample volume were estimated by total number of patients received radical hysterectomy by all means and by MIS before propensity scored matching dividing number of centers and years of recruitment that different characteristics of publication such as year and journal of publication might be a reason that led to the heterogeneous results in this study. The comparison between MIS to ARH also revealed magnificent geographical difference. Namely, studies in Asia reported that both LRH and RRH were associated with increased risk of recurrence and progression in patients with cervical cancer, which was consistent with the results reported by Hwang et al. [17]. Studies in America reported poor PFS in patients that received MIS except those with FIGO IB 1 disease while studies in Europe reported comparable DFS/PFS between MIS and ARH. Regional subgroup analyses revealed high consistency in Europe but marked heterogeneity in Asia and America. Based on the present study, we did not find any evidence opposing MIS as an alternative choice of ARH in Europe. However, the results of our study as well as most previous meta-analyses were based primarily on non-randomized studies and should be, therefore, interpreted as generating hypotheses.

Comparable oncological safeties of MIS vs. ARH and LRH vs. ARH were observed in centers with a high sample volume or high MIS sample volume but poor outcome of MIS and LRH in centers with a low sample or low MIS sample volume. A retrospective analysis involving 116 Japanese centers, where 5964 women with FIGO IB1-IIB cervical cancer underwent radical hysterectomy, revealed a significantly decreased risk for recurrence (HR 0.69; 95\% CI $0.57-0.84$ ) and death (HR 0.75 ; 95\% CI 0.59-0.95) in high-volume centers when compared with low-volume centers [74]. According to data reported by Matsuo et al., a population-based retrospective study queried the American National Inpatient Sample from 2007 to 2011, the centers 
Table 6 Sub-group analysis of studies comparing diseasefree/progression-free survival between patients undergoing $\mathrm{RRH}$ and ARH

\begin{tabular}{|c|c|c|c|c|c|c|c|}
\hline & \multirow[t]{2}{*}{ No. of studies } & \multicolumn{3}{|c|}{ No. of patients } & \multirow[t]{2}{*}{ HR $(95 \%$ CI $)$} & \multirow[t]{2}{*}{$p$ value } & \multirow[t]{2}{*}{$I^{2}$ value } \\
\hline & & RRH & $\mathrm{ARH}$ & Total & & & \\
\hline Overall analysis & 13 & 2534 & 2550 & 5084 & $1.303(1.130-1.503)$ & $<0.001$ & $\mathbf{5 7 . 9 \%}$ \\
\hline \multicolumn{8}{|c|}{ Publication time-point } \\
\hline Before LACC & 7 & 982 & 1036 & 2018 & 1.717 (1.156-2.551) & 0.007 & $0.0 \%$ \\
\hline After LACC & 6 & 1552 & 1514 & 3066 & $1.244(1.068-1.450)$ & 0.005 & $\mathbf{5 5 . 7} \%$ \\
\hline \multicolumn{8}{|l|}{ Region of journal } \\
\hline Europe & 5 & 857 & 800 & 1657 & $1.781(1.268-2.503)$ & 0.042 & $59.7 \%$ \\
\hline America & 6 & 1418 & 1308 & 2726 & 1.189 (1.015-1.394) & 0.049 & $\mathbf{5 5 . 0} \%$ \\
\hline Asia & 2 & 259 & 442 & 701 & $2.263(0.989-5.177)$ & 0.329 & $0.0 \%$ \\
\hline \multicolumn{8}{|l|}{ No. of center } \\
\hline Single center & 8 & 906 & 765 & 1670 & $1.516(0.970-2.369)$ & 0.068 & $44.2 \%$ \\
\hline Multi-center & 5 & 1629 & 1785 & 3414 & 1.277 (1.098-1.484) & 0.001 & $72.5 \%$ \\
\hline \multicolumn{8}{|l|}{ Region of center ${ }^{1}$} \\
\hline Europe & 5 & 810 & 755 & 1565 & $1.376(0.940-2.014)$ & 0.101 & $51.4 \%$ \\
\hline America & 6 & 677 & 774 & 1451 & $1.736(1.200-2.511)$ & 0.003 & $34.9 \%$ \\
\hline Asia & 2 & 1047 & 1021 & 2068 & $1.241(1.049-1.467)$ & 0.012 & $51.2 \%$ \\
\hline \multicolumn{8}{|l|}{ Sample volume ${ }^{2}$} \\
\hline High volume & 8 & 2114 & 1949 & 4063 & $1.283(1.111-1.482)$ & 0.001 & $72.7 \%$ \\
\hline Low volume & 5 & 420 & 601 & 1021 & $1.586(0.795-3.166)$ & 0.191 & $0.0 \%$ \\
\hline \multicolumn{8}{|c|}{ MIS sample volume ${ }^{2}$} \\
\hline High volume & 7 & 1134 & 928 & 2062 & $1.537(1.131-2.090)$ & 0.006 & $65.3 \%$ \\
\hline Low volume & 6 & 1400 & 1622 & 3022 & $1.258(1.072-1.477)$ & 0.005 & $43.6 \%$ \\
\hline
\end{tabular}

Data in bold style were of statistical significance to faciliate reading

$M I S$ minimally invasive surgery, $L R H$ laparoscopic radical hysterectomy, $R R H$ robotic-assisted radical hysterectomy, $A R H$ abdominal radical hysterectomy, $H R$ hazard ratio, $C I$ confidence interval

${ }^{1}$ One study was intercontinental

${ }^{2}$ Sample volume and MIS sample volume were estimated by total number of patients received radical hysterectomy by all means and by MIS before propensity scored matching dividing number of centers and years of recruitment favoring RRH were more likely to be small bed-capacity hospitals and less likely to be urban-teaching hospitals [75]. In this case, instead of being a reflection of proficiency of treatment centers, what higher RRH volume represented was just the other way around. These findings implied that whether MIS was comparable to ARH was center-associated, which was consistent with the findings by Gennari et al. that the treatment center remained a strong prognostic factor regarding recurrence-free survival (RFS) (high-volume vs. low-volume HR 0.49; 95\% CI 0.28-0.83) and OS (highvolume vs. low-volume HR 0.50; 95\% CI, 0.26-0.94) [29].

MIS was associated with increased risk of recurrence and progression in studies with a multi-center design but not in studies with a single center design. This difference might be partially due to the variances of centers involved in multi-center studies and single-center studies: ideally, in a single-center study, the center should be capable of providing sufficient number of MIS cases, while in a multi-center study, the centers with low sample volume should be limited. However, there was disproportion between number of included centers and number of patients as well as mixture of centers with different sample volume, bed capacity and different MIS technique level in several intercontinental, nation-wide and vast regional multi-center studies. Additionally, some local high-volume centers were not readily included in multi-center studies from the same region. For example, centers from studies reported by $\mathrm{He}$ et al. [60] and Yang et al. [5] were absent in the study reported by Chen et al. [40]. The absence of the local high-volume centers in multi-center studies could further augment the difference between the single-center studies and the multi-center studies and led to results favoring ARH. Compared to assessment of medical therapies, the assessment of surgical approaches was even more difficult due to heterogeneities of personal skills, surgical instruments, experiences of surgical team, 
Table 7 Sub-group analysis of studies comparing diseasefree survival/progression-free survival between FIGO IB1 patients undergoing MIS and ARH

\begin{tabular}{|c|c|c|c|c|c|c|c|}
\hline & \multirow[t]{2}{*}{ No. of studies } & \multicolumn{3}{|c|}{ No. of patients } & \multirow[t]{2}{*}{ HR $(95 \%$ CI $)$} & \multirow[t]{2}{*}{$p$ value } & \multirow[t]{2}{*}{$I^{2}$ value } \\
\hline & & MIS & ARH & Total & & & \\
\hline Overall analysis & 17 & 7168 & 6776 & 13,944 & $1.515(1.271-1.805)$ & $<0.001$ & $38.8 \%$ \\
\hline \multicolumn{8}{|l|}{ Tumor size } \\
\hline $\mathrm{IB} 1<2 \mathrm{~cm}$ & 13 & 4333 & 4042 & 8375 & $1.257(0.884-1.789)$ & 0.311 & $48.5 \%$ \\
\hline $\mathrm{IB} 1 \geq 2 \mathrm{~cm}$ & 9 & 2201 & 2055 & 4256 & $1.787(1.396-2.286)$ & 0.025 & $14.7 \%$ \\
\hline \multicolumn{8}{|l|}{ Region of center ${ }^{1}$} \\
\hline Europe & 4 & 776 & 1199 & 1975 & $1.241(0.891-1.728)$ & 0.202 & $66.4 \%$ \\
\hline America & 3 & 376 & 243 & 619 & $2.478(1.148-5.348)$ & 0.021 & $\mathbf{5 8 . 8} \%$ \\
\hline Asia & 9 & 5109 & 4452 & 9561 & $1.523(1.213-1.912)$ & $<0.001$ & $28.7 \%$ \\
\hline \multicolumn{8}{|l|}{ Surgical approach } \\
\hline LRH vs ARH & 9 & 4114 & 4368 & 8482 & $1.575(1.277-1.943)$ & $<0.001$ & $44.2 \%$ \\
\hline RRH vs ARH & 3 & 540 & 547 & 1087 & $1.502(0.729-3.095)$ & 0.270 & $5.1 \%$ \\
\hline MIS vs ARH & 6 & 2274 & 1659 & 3933 & $1.392(0.994-1.950)$ & 0.054 & $\mathbf{5 3 . 3} \%$ \\
\hline \multicolumn{8}{|l|}{ No. of centers } \\
\hline Single-center & 3 & 222 & 201 & 423 & $1.558(0.911-2.664)$ & 0.105 & $45.9 \%$ \\
\hline Multi-center & 14 & 6706 & 6373 & 13,079 & $1.513(1.264-1.812)$ & $<0.001$ & $40.1 \%$ \\
\hline \multicolumn{8}{|l|}{ Sample volume ${ }^{2}$} \\
\hline High volume & 4 & 2411 & 1523 & 3934 & $1.254(0.862-1.824)$ & 0.236 & $38.6 \%$ \\
\hline Low volume & 11 & 3947 & 4069 & 8016 & $1.739(1.397-2.165)$ & $<0.001$ & $27.4 \%$ \\
\hline Mixed volume & 2 & 570 & 982 & 1552 & $1.151(0.783-1.692)$ & 0.720 & $81.3 \%$ \\
\hline \multicolumn{8}{|c|}{ MIS sample volume ${ }^{2}$} \\
\hline High volume & 5 & 2093 & 1177 & 3270 & $1.264(0.876-1.824)$ & 0.211 & $47.3 \%$ \\
\hline Low volume & 10 & 4415 & 4265 & 8680 & 1.693 (1.354-2.118) & $<0.001$ & $14.4 \%$ \\
\hline Mixed volume & 2 & 570 & 982 & 1552 & $1.151(0.783-1.692)$ & 0.474 & $81.3 \%$ \\
\hline
\end{tabular}

Data in bold style were of statistical significance to faciliate reading

$M I S$ minimally invasive surgery, $L R H$ laparoscopic radical hysterectomy, $R R H$ robotic-assisted radical hysterectomy, $A R H$ abdominal radical hysterectomy, $H R$ hazard ratio, $C I$ confidence interval

${ }^{1}$ One study was intercontinental

${ }^{2}$ Sample volume and MIS sample volume were estimated by total number of patients received radical hysterectomy by all means and by MIS before propensity scored matching dividing number of centers and years of recruitment supportive medication of complication and adjuvant therapy, let alone a surgery as challenging as minimally invasive radical hysterectomy. Even RCTs, the most rigorous study design, were difficult to conduct rigorously in the evaluation of some complex surgical interventions [76]. Therefore, the reported increased risk of recurrence of cervical cancer associated with MIS might reflect the uneven proficiency in the MIS technique around the world rather than the inferiority of the surgical approach itself $[77,78]$. Center-associated factors such as center sample volume and experience of surgeons needed to be taken consideration in future evaluation of MIS hysterectomy.

Study inclusion was maximized and subgroup analyses based on characteristics of disease, publication, study design and treatment center were performed so as to get a general idea of actual oncological safety of MIS for cervical cancer among previous heterogeneous results. Meanwhile, several limitations came along with this study design. A few earlier studies did not report adjusting method for variable control and the cohort scale of these earlier studies was also relatively smaller as compared to that of recent multicenter studies. The sample volume and MIS sample volume for multi-center studies might not represent the actual surgical volume of each included center since most multi-center studies did not report the exact number of included patients from each center. We did not evaluate the potential impact of protective maneuvers on improving the oncological safety of the laparoscopic radical hysterectomy technique as suggested by Kampers et al. 
Table 8 Sub-group analysis of studies comparing diseasefree survival/progression-free survival between FIGO IB1 patients with tumor size $<2 \mathrm{~cm}$ undergoing MIS and ARH

\begin{tabular}{|c|c|c|c|c|c|c|c|}
\hline & \multirow[t]{2}{*}{ No. of studies } & \multicolumn{3}{|c|}{ No. of patients } & \multirow[t]{2}{*}{$\mathrm{HR}(95 \% \mathrm{CI})$} & \multirow[t]{2}{*}{$p$ value } & \multirow[t]{2}{*}{$I^{2}$ value } \\
\hline & & MIS & ARH & Total & & & \\
\hline FIGO IB $1<2 \mathrm{~cm}$ & 13 & 4333 & 4042 & 8375 & $1.257(0.884-1.789)$ & 0.311 & $48.5 \%$ \\
\hline \multicolumn{8}{|l|}{ Region of center ${ }^{1}$} \\
\hline Europe & 2 & 320 & 365 & 685 & $0.516(0.281-0.945)$ & 0.032 & $0.0 \%$ \\
\hline America & 2 & 212 & 103 & 315 & $3.569(0.990-12.867)$ & 0.052 & $20.4 \%$ \\
\hline Asia & 8 & 3315 & 3082 & 6397 & 1.398 (1.061-1.843) & 0.017 & $31.5 \%$ \\
\hline \multicolumn{8}{|l|}{ Surgical approach } \\
\hline LRH vs ARH & 8 & 2748 & 2961 & 5709 & $1.291(1.007-1.655)$ & 0.044 & $\mathbf{5 4 . 8} \%$ \\
\hline RRH vs ARH & 2 & 521 & 512 & 1033 & $1.285(0.565-2.924)$ & 0.550 & $0.0 \%$ \\
\hline MIS vs ARH & 3 & 1064 & 569 & 1633 & $1.075(0.562-2.059)$ & 0.826 & $73.4 \%$ \\
\hline \multicolumn{8}{|l|}{ Sample volume ${ }^{2}$} \\
\hline High volume & 4 & 1474 & 988 & 2462 & $0.852(0.543-1.338)$ & 0.487 & $0.0 \%$ \\
\hline Low volume & 8 & 2676 & 2803 & 5479 & $1.552(1.190-2.024)$ & 0.001 & $38.5 \%$ \\
\hline Mixed volume & 1 & 183 & 251 & 434 & $0.440(0.160-1.270)$ & - & - \\
\hline \multicolumn{8}{|c|}{ MIS sample volume ${ }^{2}$} \\
\hline High volume & 3 & 983 & 497 & 1480 & $0.745(0.442-1.255)$ & 0.269 & $0.0 \%$ \\
\hline Low volume & 9 & 3167 & 3294 & 6461 & $1.527(1.183-1.969)$ & 0.001 & $30.9 \%$ \\
\hline Mixed volume & 1 & 183 & 251 & 434 & $0.440(0.160-1.270)$ & - & - \\
\hline
\end{tabular}

Data in bold style were of statistical significance to faciliate reading

$M I S$ minimally invasive surgery, $L R H$ laparoscopic radical hysterectomy, $R R H$ robotic-assisted radical hysterectomy, $A R H$ abdominal radical hysterectomy, $H R$ hazard ratio, $C I$ confidence interval

${ }^{1}$ One study was intercontinental

${ }^{2}$ Sample volume and MIS sample volume were estimated by total number of patients received radical hysterectomy by all means and by MIS before propensity scored matching dividing number of centers and years of recruitment

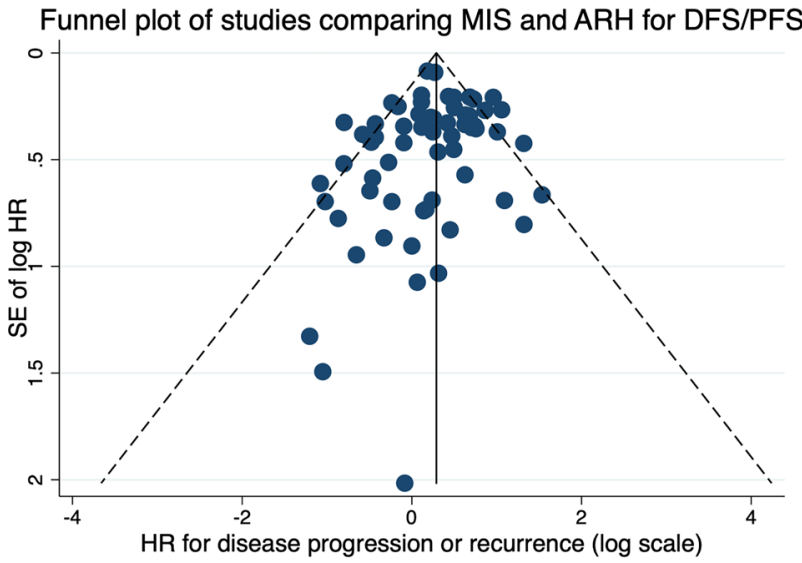

Fig. 2 Funnel plots for studies comparing disease-free survival/progression-free survival

[79]. And we failed to perform stratified analyses based on the proficiency of the treatment center and the MIS technique of the surgeons.

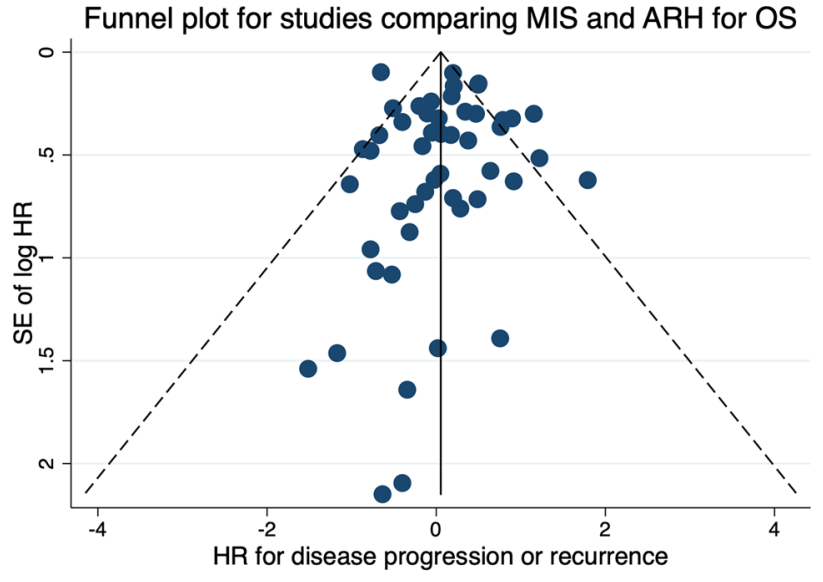

Fig. 3 Funnel plots for studies comparing overall survival

\section{Conclusions}

Our findings highlight possible factors that contributed to inferior performance of MIS in cervical cancer including publication characteristics, center-geography and sample volume. Center associated factors were needed to be taken 
into consideration when evaluating complex surgical procedures like radical hysterectomy.

Supplementary Information The online version contains supplementary material available at https://doi.org/10.1007/s00404-021-06348-5.

Author contributions ZW and JC designed the study. SS and QY conducted study search. SS and LX conducted study selection and quality control. RL, YW, JZ and YH collected data. SS and QY validated data. SS and QY performed statistical analysis. JC reviewed the reliability of the results. SS and JC prepared the manuscript and figures. ZW, JC and SS were involved in manuscript revision and editing. All authors reviewed and approved the final version of the manuscript.

Funding This work was supported by the National Natural Science Foundation of China (81974413).

\section{Declarations}

Conflict of interest The authors have no relevant financial or non-financial interests to disclose.

Ethical approval Not applicable.

Open Access This article is licensed under a Creative Commons Attribution 4.0 International License, which permits use, sharing, adaptation, distribution and reproduction in any medium or format, as long as you give appropriate credit to the original author(s) and the source, provide a link to the Creative Commons licence, and indicate if changes were made. The images or other third party material in this article are included in the article's Creative Commons licence, unless indicated otherwise in a credit line to the material. If material is not included in the article's Creative Commons licence and your intended use is not permitted by statutory regulation or exceeds the permitted use, you will need to obtain permission directly from the copyright holder. To view a copy of this licence, visit http://creativecommons.org/licenses/by/4.0/.

\section{References}

1. Ramirez PT, Frumovitz M, Pareja R, Lopez A, Vieira M, Ribeiro $R$ et al (2018) Minimally Invasive versus Abdominal Radical Hysterectomy for Cervical Cancer. N Engl J Med 379(20):1895-1904

2. Melamed A, Margul DJ, Chen L, Keating NL, Del Carmen MG, Yang J et al (2018) Survival after minimally invasive radical hysterectomy for early-stage cervical cancer. N Engl J Med 379(20):1905-1914

3. National Comprehensive Cancer Network (NCCN) (2021) Clinical Practice Guidelines in Oncology. Cervical Cancer, version 1. 2021

4. Mendivil AA, Rettenmaier MA, Abaid LN, Brown JV 3rd, Micha JP, Lopez KL et al (2016) Survival rate comparisons amongst cervical cancer patients treated with an open, robotic-assisted or laparoscopic radical hysterectomy: a five year experience. Surg Oncol 25(1):66-71

5. Yang L, Yang P, Li D, Cai J, Shen Y, Dong W et al (2015) Comparison of safety and efficacy of laparoscopic versus abdominal radical hysterectomy in the treatment of patients with stage I a2-II b cervical cancer. Zhonghua Fu Chan Ke Za Zhi 50(12):915-922

6. Bogani G, Cromi A, Uccella S, Serati M, Casarin J, Pinelli C et al (2014) Laparoscopic versus open abdominal management of cervical cancer: long-term results from a propensity-matched analysis. J Minim Invasive Gynecol 21(5):857-862

7. Choi CH, Lee JW, Lee YY, Kim HJ, Song T, Kim MK et al (2012) Comparison of laparoscopic-assisted radical vaginal hysterectomy and laparoscopic radical hysterectomy in the treatment of cervical cancer. Ann Surg Oncol 19(12):3839-3848

8. Cantrell LA, Mendivil A, Gehrig PA, Boggess JF (2010) Survival outcomes for women undergoing type III robotic radical hysterectomy for cervical cancer: a 3-year experience. Gynecol Oncol 117(2):260-265

9. Wang YZ, Deng L, Xu HC, Zhang Y, Liang ZQ (2015) Laparoscopy versus laparotomy for the management of early stage cervical cancer. BMC Cancer 15:928

10. Cao T, Feng Y, Huang Q, Wan T, Liu J (2015) Prognostic and safety roles in laparoscopic versus abdominal radical hysterectomy in cervical cancer: a meta-analysis. J Laparoendosc Adv Surg Tech A 25(12):990-998

11. Rodriguez J, Rauh-Hain JA, Saenz J, Isla DO, Rendon Pereira GJ, Odetto D et al (2021) Oncological outcomes of laparoscopic radical hysterectomy versus radical abdominal hysterectomy in patients with early-stage cervical cancer: a multicenter analysis. Int J Gynecol Cancer 31(4):504-511

12. Yang J, Mead-Harvey C, Polen-De C, Magtibay P, Butler K, Cliby $\mathrm{W}$ et al (2020) Survival outcomes in patients with cervical cancer treated with open versus robotic radical hysterectomy: our surgical pathology interrogation. Gynecol Oncol 159(2):373-380

13. Uppal S, Gehrig PA, Peng K, Bixel KL, Matsuo K, Vetter MH et al (2020) Recurrence rates in patients with cervical cancer treated with abdominal versus minimally invasive radical hysterectomy: a multi-institutional retrospective review study. J Clin Oncol 38(10):1030-1040

14. Dai D, Huang H, Feng Y, Wan T, Liu Z, Tong C et al (2020) Minimally invasive surgery vs laparotomy for early stage cervical cancer: a propensity score-matched cohort study. Cancer Med 9(24):9236-9245

15. Tantitamit T, Huang KG, Lee CL (2020) Laparoscopic versus open radical hysterectomy in women with early stage cervical cancer: a systematic review and meta-analysis. Taiwan J Obstet Gynecol 59(4):481-488

16. Nitecki R, Ramirez PT, Frumovitz M, Krause KJ, Tergas AI, Wright JD et al (2020) Survival after minimally invasive vs open radical hysterectomy for early-stage cervical cancer: a systematic review and meta-analysis. JAMA Oncol 6(7):1-9

17. Hwang JH, Kim BW (2020) Comparison of survival outcomes after laparoscopic radical hysterectomy versus abdominal radical hysterectomy in patients with cervical cancer. J Minim Invasive Gynecol 28:971-981

18. Yuce TK, Ellis RJ, Chung J, Merkow RP, Yang AD, Soper NJ et al (2020) Association between surgical approach and survival following resection of abdominopelvic malignancies. J Surg Oncol 121(4):620-629

19. Walker JL, Piedmonte MR, Spirtos NM, Eisenkop SM, Schlaerth JB, Mannel RS et al (2009) Laparoscopy compared with laparotomy for comprehensive surgical staging of uterine cancer: Gynecologic Oncology Group Study LAP2. J Clin Oncol 27(32):5331-5336

20. Obermair A, Janda M, Baker J, Kondalsamy-Chennakesavan S, Brand A, Hogg R et al (2012) Improved surgical safety after laparoscopic compared to open surgery for apparent early stage endometrial cancer: results from a randomised controlled trial. Eur J Cancer (Oxf, Engl) 48(8):1147-1153

21. Dietl A, Klar M, Aumann K (2019) Minimally invasive surgery for early-stage cervical cancer: is the uterine manipulator a risk factor? Am J Obstet Gynecol 221(5):537-538

22. Li LY, Wen LY, Park SH, Nam EJ, Lee JY, Kim S et al (2021) Impact of the learning curve on the survival of abdominal or 
minimally invasive radical hysterectomy for early-stage cervical cancer. Cancer Res Treat 53(1):243-251

23. Tierney JF, Stewart LA, Ghersi D, Burdett S, Sydes MR (2007) Practical methods for incorporating summary time-to-event data into meta-analysis. Trials 8:16

24. DerSimonian R, Laird N (1986) Meta-analysis in clinical trials. Control Clin Trials 7(3):177-188

25. Higgins JP, Thompson SG (2002) Quantifying heterogeneity in a meta-analysis. Stat Med 21(11):1539-1558

26. Zaccarini F, Santy A, Dabi Y, Lavoue V, Carcopino X, Bendifallah $S$ et al (2021) Comparison of survival outcomes between laparoscopic and abdominal radical hysterectomy for early-stage cervical cancer: a French multicentric study. J Gynecol Obstet Hum Reprod 50(2):102046

27. Levine MD, Brown J, Crane EK, Tait DL, Naumann RW (2021) Outcomes of minimally invasive versus open radical hysterectomy for early stage cervical cancer incorporating 2018 FIGO staging. J Minim Invasive Gynecol 28(4):824-828

28. Kim SI, Lee J, Hong J, Lee SJ, Park DC, Yoon JH (2021) Comparison of abdominal and minimally invasive radical hysterectomy in patients with early stage cervical cancer. Int J Med Sci 18(5):1312-1317

29. Gennari P, Gerken M, Mészáros J, Klinkhammer-Schalke M, Ortmann O, Eggemann H et al (2021) Minimal-invasive or open approach for surgery of early cervical cancer: the treatment center matters. Arch Gynecol Obstet 304:503-510

30. Yang W, Chen R, Li C, Li L, Luo N, Cheng Z (2020) Laparoscopic regional radical hysterectomy showed promising clinical outcomes in early-stage cervical cancer. Gynecol Minim Invasive Ther 9(4):220-226

31. Wenzel HHB, Smolders RGV, Beltman JJ, Lambrechts S, Trum HW, Yigit R et al (2020) Survival of patients with early-stage cervical cancer after abdominal or laparoscopic radical hysterectomy: a nationwide cohort study and literature review. Eur J Cancer (Oxf, Engl) 133:14-21

32. Qin M, Siyi L, Huang HF, Li Y, Gu Y, Wang W et al (2020) A Comparison of laparoscopies and laparotomies for radical hysterectomy in stage IA1-IB1 cervical cancer patients: a single team with 18 years of experience. Front Oncol 10:1738

33. Pedone Anchora L, Turco LC, Bizzarri N, Capozzi VA, Lombisani A, Chiantera V et al (2020) How to select early-stage cervical cancer patients still suitable for laparoscopic radical hysterectomy: a propensity-matched study. Ann Surg Oncol 27(6):1947-1955

34. Hu TWY, Huang Y, Li N, Nie D, Li Z (2020) Comparison of laparoscopic versus open radical hysterectomy in patients with early-stage cervical cancer: a multicenter study in China. Int $\mathrm{J}$ Gynecol Cancer 30:1143-1150

35. He J, Hao M, Liu P, Liu Z, Lang J, Bin X et al (2020) Comparison of laparoscopic and abdominal radical hysterectomy for early stage cervical cancer: oncologic outcomes based on tumor diameter. Int J Gynecol Cancer 30:1308-1316

36. Guo C, Tang X, Meng Y, Zhang Y, Zhang X, Guo J et al (2020) Effect of the surgical approach on survival outcomes in patients undergoing radical hysterectomy for cervical cancer: a real-world multicenter study of a large Chinese cohort from 2006 to 2017. Cancer Med 9:5908-5921

37. Eoh KJ, Lee JY, Nam EJ, Kim S, Kim SW, Kim YT (2020) The institutional learning curve is associated with survival outcomes of robotic radical hysterectomy for early-stage cervical cancer-a retrospective study. BMC Cancer 20(1):152

38. Chiva L, Zanagnolo V, Querleu D, Martin-Calvo N, ArévaloSerrano J, Căpîlna ME et al (2020) SUCCOR study: an international European cohort observational study comparing minimally invasive surgery versus open abdominal radical hysterectomy in patients with stage IB1 cervical cancer. Int J Gynecol Cancer 30(9):1269-1277
39. Chen X, Zhao N, Ye P, Chen J, Nan X, Zhao H et al (2020) Comparison of laparoscopic and open radical hysterectomy in cervical cancer patients with tumor size $\leq 2 \mathrm{~cm}$. Int J Gynecol Cancer 30(5):564-571

40. Chen C, Liu P, Ni Y, Tang L, Xu Y, Bin X et al (2020) Laparoscopic versus abdominal radical hysterectomy for stage IB 1 cervical cancer patients with tumor size $\leq 2 \mathrm{~cm}$ : a case-matched control study. Int J Clin Oncol 25(5):937-947

41. Chen B, Ji M, Li P, Liu P, Zou W, Zhao Z et al (2020) Comparison between robot-assisted radical hysterectomy and abdominal radical hysterectomy for cervical cancer: a multicentre retrospective study. Gynecol Oncol 157(2):429-436

42. Brandt B, Sioulas V, Basaran D, Kuhn T, LaVigne K, Gardner GJ et al (2020) Minimally invasive surgery versus laparotomy for radical hysterectomy in the management of early-stage cervical cancer: survival outcomes. Gynecol Oncol 156(3):591-597

43. Bogani G, Ghezzi F, Chiva L, Gisone B, Pinelli C, Dell'Acqua A et al (2020) Patterns of recurrence after laparoscopic versus open abdominal radical hysterectomy in patients with cervical cancer: a propensity-matched analysis. Int J Gynecol Cancer 30(7):987-992

44. Yuan Z, Cao D, Yang J, Yu M, Shen K, Yang J et al (2019) Laparoscopic vs. open abdominal radical hysterectomy for cervical cancer: a single-institution, propensity score matching study in China. Front Oncol 9:1107

45. Ratiu D, Luncescu C, Morgenstern B, Eichler C, Grüttner B, Ludwig $\mathrm{S}$ et al (2019) Comparison of minimally invasive surgery and abdominal surgery among patients with cervical cancer. Anticancer Res 39(5):2661-2664

46. Paik ES, Lim MC, Kim MH, Kim YH, Song ES, Seong SJ et al (2019) Comparison of laparoscopic and abdominal radical hysterectomy in early stage cervical cancer patients without adjuvant treatment: ancillary analysis of a Korean Gynecologic Oncology Group Study (KGOG 1028). Gynecol Oncol 154(3):547-553

47. Matanes E, Abitbol J, Kessous R, Kogan L, Octeau D, Lau S et al (2019) Oncologic and surgical outcomes of robotic versus open radical hysterectomy for cervical cancer. J Obstet Gynaecol Can JOGC 41(4):450-458

48. Liu Y, Li L, Wu M, Ma S, Tan X, Zhong S et al (2019) The impact of the surgical routes and learning curve of radical hysterectomy on the survival outcomes in stage IB cervical cancer: a retrospective cohort study. Int J Surg (Lond, Engl) 68:72-77

49. Kim SI, Lee M, Lee S, Suh DH, Kim HS, Kim K et al (2019) Impact of laparoscopic radical hysterectomy on survival outcome in patients with FIGO stage IB cervical cancer: a matching study of two institutional hospitals in Korea. Gynecol Oncol 155(1):75-82

50. Kim JH, Kim K, Park SJ, Lee JY, Kim K, Lim MC et al (2019) Comparative Effectiveness of abdominal versus laparoscopic radical hysterectomy for cervical cancer in the postdissemination era. Cancer Res Treat 51(2):788-796

51. Kanao H, Matsuo K, Aoki Y, Tanigawa T, Nomura H, Okamoto $S$ et al (2019) Feasibility and outcome of total laparoscopic radical hysterectomy with no-look no-touch technique for FIGO IB1 cervical cancer. J Gynecol Oncol 30(3):e71

52. Gil-Moreno A, Carbonell-Socias M, Salicrú S, Centeno-Mediavilla C, Franco-Camps S, Colas E et al (2019) Radical hysterectomy: efficacy and safety in the dawn of minimally invasive techniques. J Minim Invasive Gynecol 26(3):492-500

53. Doo DW, Kirkland CT, Griswold LH, McGwin G, Huh WK, Leath CA 3rd et al (2019) Comparative outcomes between robotic and abdominal radical hysterectomy for IB1 cervical cancer: Results from a single high volume institution. Gynecol Oncol 153(2):242-247

54. Cusimano MC, Baxter NN, Gien LT, Moineddin R, Liu N, Dossa $F$ et al (2019) Impact of surgical approach on oncologic outcomes 
in women undergoing radical hysterectomy for cervical cancer. Am J Obstet Gynecol 221(6):619.e1-e24

55. Alfonzo E, Wallin E, Ekdahl L, Staf C, Rådestad AF, Reynisson $P$ et al (2019) No survival difference between robotic and open radical hysterectomy for women with early-stage cervical cancer: results from a nationwide population-based cohort study. Eur $\mathbf{J}$ Cancer (Oxf, Engl) 116:169-177

56. Guo J, Yang L, Cai J, Xu L, Min J, Shen Y et al (2018) Laparoscopic procedure compared with open radical hysterectomy with pelvic lymphadenectomy in early cervical cancer: a retrospective study. Onco Targets Ther 11:5903-5908

57. Corrado G, Vizza E, Legge F, Pedone Anchora L, Sperduti I, Fagotti A et al (2018) Comparison of different surgical approaches for stage IB1 cervical cancer patients: a multi-institution study and a review of the literature. Int J Gynecol Cancer 28(5):1020-1028

58. Wallin E, Floter Radestad A, Falconer H (2017) Introduction of robot-assisted radical hysterectomy for early stage cervical cancer: impact on complications, costs and oncologic outcome. Acta Obstet Gynecol Scand 96(5):536-542

59. Shah CA, Beck T, Liao JB, Giannakopoulos NV, Veljovich D, Paley P (2017) Surgical and oncologic outcomes after robotic radical hysterectomy as compared to open radical hysterectomy in the treatment of early cervical cancer. J Gynecol Oncol 28(6):e82

60. He HY, Yang ZJ, Zeng DY, Yao DS, Fan JT, Zhao RF et al (2017) Comparison of the short-term and long-term outcomes of laparoscopic surgery and open surgery for early-stage cervical cancer. Zhonghua zhong liu za zhi [Chin J Oncol] 39(6):458-466

61. Diver E, Hinchcliff E, Gockley A, Melamed A, Contrino L, Feldman S et al (2017) Minimally invasive radical hysterectomy for cervical cancer is associated with reduced morbidity and similar survival outcomes compared with laparotomy. J Minim Invasive Gynecol 24(3):402-406

62. Zanagnolo V, Minig L, Rollo D, Tomaselli T, Aletti G, Bocciolone L et al (2016) Clinical and oncologic outcomes of robotic versus abdominal radical hysterectomy for women with cervical cancer: experience at a referral cancer center. Int J Gynecol Cancer 26(3):568-574

63. Wang W, Chu HJ, Shang CL, Gong X, Liu TY, Zhao YH et al (2016) Long-term oncological outcomes after laparoscopic versus abdominal radical hysterectomy in stage IA2 to IIA2 cervical cancer: a matched cohort study. Int J Gynecol Cancer 26(7):1264-1273

64. Sert BM, Boggess JF, Ahmad S, Jackson AL, Stavitzski NM, Dahl AA et al (2016) Robot-assisted versus open radical hysterectomy: a multi-institutional experience for early-stage cervical cancer. Eur J Surg Oncol 42(4):513-522

65. Xiao M, Zhang Z (2015) Total laparoscopic versus laparotomic radical hysterectomy and lymphadenectomy in cervical cancer: an observational study of 13-year experience. Medicine 94(30):e1264

66. Ditto A, Martinelli F, Bogani G, Gasparri ML, Di Donato V, Zanaboni $\mathrm{F}$ et al (2015) Implementation of laparoscopic approach for type B radical hysterectomy: a comparison with open surgical operations. Eur J Surg Oncol 41(1):34-39

67. Toptas T, Simsek T (2014) Total laparoscopic versus open radical hysterectomy in stage IA2-IB1 cervical cancer: disease recurrence and survival comparison. J Laparoendosc Adv Surg Tech A 24(6):373-378

68. Park JY, Kim DY, Kim JH, Kim YM, Kim YT, Nam JH (2013) Laparoscopic versus open radical hysterectomy in patients with stage IB2 and IIA2 cervical cancer. J Surg Oncol 108(1):63-69

69. Nam JH, Park JY, Kim DY, Kim JH, Kim YM, Kim YT (2012) Laparoscopic versus open radical hysterectomy in early-stage cervical cancer: long-term survival outcomes in a matched cohort study. Ann Oncol 23(4):903-911

70. Yang ZJ, Chen YL, Yao DS, Zhang JQ, Li F, Li L (2011) Impact on survival and quality of life of laparoscopic radical hysterectomy and pelvic lymphadenectomy to patients with early-stage cervical cancer. Zhonghua Fu Chan Ke Za Zhi 46(11):854-859

71. Lee EJ, Kang H, Kim DH (2011) A comparative study of laparoscopic radical hysterectomy with radical abdominal hysterectomy for early-stage cervical cancer: a long-term follow-up study. Eur J Obstet Gynecol Reprod Biol 156(1):83-86

72. Sobiczewski P, Bidzinski M, Derlatka P, Panek G, Danska-Bidzinska A, Gmyrek L et al (2009) Early cervical cancer managed by laparoscopy and conventional surgery: comparison of treatment results. Int J Gynecol Cancer 19(8):1390-1395

73. Malzoni M, Tinelli R, Cosentino F, Fusco A, Malzoni C (2009) Total laparoscopic radical hysterectomy versus abdominal radical hysterectomy with lymphadenectomy in patients with early cervical cancer: our experience. Ann Surg Oncol 16(5):1316-1323

74. Matsuo K, Shimada M, Yamaguchi S, Matoda M, Nakanishi T, Kikkawa F et al (2019) Association of radical hysterectomy surgical volume and survival for early-stage cervical cancer. Obstet Gynecol 133(6):1086-1098

75. Matsuo K, Matsuzaki S, Mandelbaum RS, Chang EJ, Klar M, Matsushima K et al (2020) Minimally invasive radical hysterectomy for early-stage cervical cancer: volume-outcome relationship in the early experience period. Gynecol Oncol 158(2):390-396

76. Farrokhyar F, Karanicolas PJ, Thoma A, Simunovic M, Bhandari M, Devereaux PJ et al (2010) Randomized controlled trials of surgical interventions. Ann Surg 251(3):409-416

77. Liu Y, Huang S, Ming X, Jing H, Li Z (2021) Surgical approach and use of uterine manipulator are not associated with lvsi in surgery for early-stage cervical cancer. J Minim Invasive Gynecol 28:1573-1578

78. Nica A, Kim SR, Gien LT, Covens A, Bernardini MQ, BouchardFortier G et al (2020) Survival after minimally invasive surgery in early cervical cancer: is the intra-uterine manipulator to blame? Int J Gynecol Cancer 30(12):1864-1870

79. Kampers J, Gerhardt E, Sibbertsen P, Flock T, Klapdor R, Hertel $\mathrm{H}$ et al (2021) Protective operative techniques in radical hysterectomy in early cervical carcinoma and their influence on diseasefree and overall survival: a systematic review and meta-analysis of risk groups. Arch Gynecol Obstet 304(3):577-587

Publisher's Note Springer Nature remains neutral with regard to jurisdictional claims in published maps and institutional affiliations. 